\title{
A population-based study of Ashkenazi Jewish women's attitudes toward genetic discrimination and BRCA1/2 testing
}

Lisa Soleymani Lehmann, MD, MSc ${ }^{1}$, Jane C. Weeks, MD, MSc ${ }^{2}$, Neil Klar, PhD ${ }^{3}$, and Judy E. Garber, MD, MPH

\begin{abstract}
Purpose: The Human Genome Project continues to produce an increasing number of genetic susceptibility tests. Some of these genetic tests target social or ethnic groups who are at increased risk of developing a disease. The Ashkenazi Jewish community is one ethnic group that is an ongoing subject of genetic investigation. We assessed the attitudes of a population-based sample of Ashkenazi Jewish women toward breast-ovarian cancer susceptibility testing (BRCA1/2). In particular, we assessed concerns about group discrimination, perceptions of the advantages and disadvantages of $B R C A 1 / 2$ testing, and the relationship between concerns about discrimination and the potential benefits of genetic testing. Methods: A telephone survey of a population-based sample of 200 Jewish women. Results: A minority of women (17\%) in this study expressed concern or discomfort with Jews being offered BRCA1/2 testing. Most women believed there were scientific reasons for testing Jews ( $71 \%$ ), and only $5 \%$ of women felt that research that focused on Jews was bad for Jews as a group. Increased concern about genetic discrimination was associated with women who were highly educated (odds ratio 2.68). Forty percent of women surveyed were interested in BRCA1/2 testing, $40 \%$ were not interested, and $20 \%$ were uncertain about whether they would obtain $B R C A 1 / 2$ testing. Increased interest in genetic testing was associated with a desire to obtain information about children's risk of disease and valuing information for its own sake. Conclusions: The majority of a population-based sample of Jewish women did not express concerns about group discrimination resulting from genetic testing. Women who are highly educated are more concerned about genetic discrimination. There is significant variation among Jewish women's interest in breast cancer susceptibility testing. Genet Med 2002:4(5):
\end{abstract}

346-352.

Key Words: genetic testing, BRCA1/2, genetic discrimination, Ashkenazi Jews

With the recent completion of the sequencing of the human genome, ${ }^{1,2}$ physicians and patients will soon have access to a growing number of genetic tests for susceptibility to late onset diseases. Presymptomatic testing for susceptibility to coronary artery disease, ${ }^{3}$ a variety of inherited cancers ${ }^{4-9}$ and Alzheimer's disease ${ }^{10}$ already exist. Although the practical purpose of these tests is to identify high-risk individuals so that they can take steps to prevent the disease for which they are at increased risk, concerns have been raised about the potential misuse of genetic information by third parties. The possibility of discrimination in access to insurance and employment ${ }^{11,12}$ may

\footnotetext{
From ${ }^{1}$ Massachusetts General Hospital, General Medicine Division, currently at Brigham and Women's Hospital, Division of General Medicine and Harvard Medical School, Division of Medical Ethics, Boston, Massachusetts; ${ }^{2}$ Department of Adult Oncology, Dana-Farber Cancer Institute, Boston, Massachusetts; and ${ }^{3}$ Department of Biostatistics, Dana-Farber Cancer Institute, Boston, Massachusetts.

Lisa S. Lehmann, MD, MSc, Brigham and Women's Hospital, Department of Medicine, 75 Francis Street, Boston, MA 02115.

Received: March 4, 2002.

Accepted: June 7, 2002.
}

DOI: 10.1097/01.GIM.0000029069.64884.66 inhibit individuals from obtaining genetic information and may also impede the progress of research that is uncovering the genetic basis of disease.

Efforts to understand the information derived from the $\mathrm{Hu}-$ man Genome Project frequently take advantage of the genetic homogeneity of certain ethnic groups. Ethnic origin is relevant to genetic testing because the distribution of genetic traits may vary among diverse ethnic populations. When genetically identifiable populations can trace their origin to a relatively restricted set of ancestors or "founders," specific mutations common to the particular group may be discovered. This concept, known as the "founder effect," is significant to our understanding of the genetics of diseases commonly found within particular ethnic groups, has implications for genetic testing strategies, and is the scientific basis for concerns about discrimination resulting from research and genetic testing within particular populations.

The study of particular ethnic groups has been facilitated by the identification of founder mutations. ${ }^{13}$ Examples of founder mutations within the Ashkenazi Jewish population include mutations associated with Tay Sachs disease and Gaucher disease. Although the Jewish community has welcomed 
screening for these genetic disorders, ${ }^{14}$ a history of misuse of population-based genetic screening in other ethnic groups has fueled increased concern about the potential for genetic discrimination among Ashkenazi Jews. One historical example of a misuse of population-based screening is sickle cell anemia, a condition that primarily affects a particular racial group, African Americans. Screening for sickle cell anemia initially resulted in significant discrimination against African Americans. ${ }^{15,16}$ More recently, concerns about the potential for group stigmatization and discrimination have been raised for Icelandic individuals ${ }^{17}$ and Ashkenazi Jews. ${ }^{18}$

Ashkenazi Jews have an increased frequency of founder mutations in BRCA1/2 and therefore have an increased rate of inherited breast and ovarian cancers. ${ }^{19-21}$ They have also been found to be at high risk for the APC I1307K allele associated with the development of colon cancer. ${ }^{22,23}$ The potential benefits of the recognition of these mutations include increased surveillance and the possibility of preventing disease. However, the social and economic consequences of being labeled "at risk" for certain diseases has led some community leaders to discourage genetic testing that targets the Jewish population. Some community leaders have suggested that Jewish women not pursue genetic testing for BRCA1/2 out of concern for stigmatization and discrimination against Jews as a group..$^{24,25}$ There has been little information, however, assessing the attitudes toward genetic cancer predisposition testing among those whom are most likely to obtain genetic testing. We performed a population-based survey to determine the attitudes of Jewish women toward the potential social consequences of $B R C A 1 / 2$ testing and the potential advantages and uses of genetic information.

\section{METHODS}

\section{Sample design}

The sample frame for the current study was a subset of respondents to a 1995 demographic survey of 1200 Jewish families in the Boston metropolitan area. ${ }^{26}$ The purpose of the demographic survey was to provide a comprehensive evaluation of the greater Boston Jewish community. The 1995 study relied on a dual frame design ${ }^{1}$ using a random sample drawn from a list of likely Jewish residences of families known to the Combined Jewish Philanthropies (CJP) of Boston and ${ }^{2}$ a sample generated using random digit dialing (RDD) of working numbers that were not on the CJP list. The response rate for the 1995 survey was 68\%. Eighty-two percent of respondents interviewed in that survey agreed to be recontacted for future research and constituted the sample frame for the current study.

\section{Eligibility criteria}

Women between the ages of 18 and 70 reporting at least one parent of Jewish descent were eligible for participation. ${ }^{17,27}$ Respondents needed to understand and speak English and be well enough to participate in a telephone interview. Before the survey, we conducted a screening interview for eligibility with each potential respondent. When a household contained more than one eligible woman, the respondent was randomly selected.

\section{Selection of respondents}

The selection of study respondents is displayed in Figure 1. Of a total of 641 telephone numbers called, contact was established with 536, and eligibility was assessed in 430 households. We determined that 207 households were eligible because they contained a resident woman between ages 18 and 70 who had at least one Jewish parent. Interviews were completed with 200 of these women for a completion rate of $97 \%$. Eligibility could not be fully determined in 106 cases either because the residents declined to complete the screening interview $(N=61)$, or because the residents neither completed the screening nor gave a final refusal $(N=45)$. Using the eligibility rate from the successfully screened cases, we estimate that 51 of 106 incompletely screened cases would have been eligible. Interviews were completed with 200 of the 258 cases assumed eligible, for an overall response rate of $78 \%$.

\section{Data collection}

Data collection occurred from July 9, 1998 to September 25, 1998. Interviewing was conducted from a central interviewing facility at the Center for Survey Research (CSR), University of Massachusetts, Boston using computer assisted telephone interviewing software. Thirteen experienced and trained women interviewers conducted the interviews. The average interview was 34 minutes.

\section{Instrument}

The study instrument was developed after 3 focus groups, 4 cognitive interviews, and 21 pretest interviews. Cognitive interviews consisted of face-to-face interviews using verbal probing to gain insight into the cognitive processes of respondents and to understand how respondents' process complex terminology. The sections focused on (1) prior experience with genetic testing, (2) knowledge of $B R C A 1 / 2$ (breast cancer susceptibility genes BRCA1 and BRCA2), (3) concerns about discrimination, (4) perceptions of advantages and disadvantages of BRCA1/2 testing, (5) use of information from $B R C A 1 / 2$ testing, and (6) sociodemographic information.

Respondents were queried about prior experience with prenatal genetic testing and Tay Sachs testing. Respondents were also asked to evaluate the usefulness of the information they obtained from prior genetic tests.

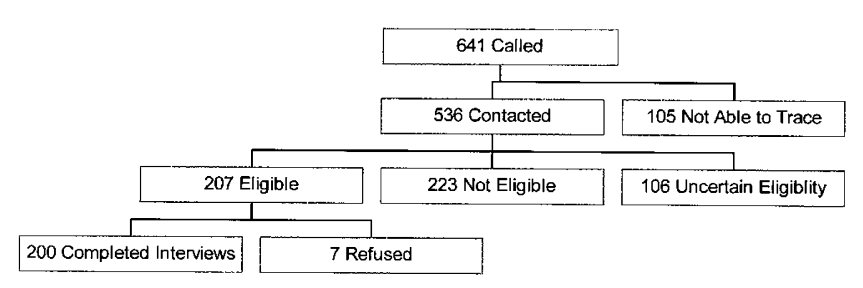

Fig. 1 Schema of cohort composition. 
Knowledge of BRCA1/2 genetics was measured using 7 questions adapted from an 11-item true/false scale developed by Lerman et al. ${ }^{28}$ Knowledge scores were created by taking the sum of the correct responses to the 7-item knowledge scale.

Concerns about group discrimination against Jews were assessed by asking respondents the following five questions: (1) Do you think there are scientific reasons for offering this genetic test to Jewish women? (2) Do you have any concern or discomfort about Jewish women being offered this genetic test? (3) Do you think participating in this testing will lead to increased anti-Semitism? (4) Do you think this testing reflects an underlying belief that Jews are genetically inferior? and (5) Do you think research that looks for specific genes common to Jews as a group is good or bad or neither? Response options for these questions were yes, no, and uncertain.

Potential advantages and disadvantages of $B R C A 1 / 2$ testing were identified from the literature. ${ }^{26}$ We asked about the following three potential advantages of genetic testing: obtaining information about the likelihood of developing a disease in the future, increased surveillance that may lead to diagnosing breast cancer at an earlier stage, and obtaining information about children's risk of breast cancer. We also asked about the following potential disadvantages of genetic testing: difficulty obtaining health insurance, employment discrimination, increased anxiety resulting from knowledge of carrying a genetic mutation, and the uncertainty of not knowing when breast cancer will develop among mutation carriers. Respondents were asked to rate the magnitude of each problem on a scale from 1 to 10. The ordering of the series of questions about the advantages and disadvantages of genetic testing was alternated for consecutive respondents. After assessing perceptions of the advantages and disadvantages of genetic testing, respondents were asked if they would be interested in being tested for a genetic susceptibility to breast cancer. Response options to this question were yes, no, and uncertain. Individuals were never offered genetic testing during this survey.

To increase the likelihood of respondents arriving at stable decisions regarding genetic testing, we felt that a minimum amount of education about BRCA1/2 testing was necessary. We, therefore, incorporated into the survey basic information about the definition of a genetic test, genes, the medical options for women who have a known BRCA1/2 mutation, and a list of the advantages and disadvantages of BRCA1/2 testing. Our questions about interest in genetic testing and concerns about genetic discrimination succeeded the sections in which general information about BRCA1/2 testing was communicated.

\section{Statistical analysis}

Frequency data and statistical associations were calculated for the characteristics of respondents, concerns about group discrimination, and use of information from BRCA1/2 testing. Analysis of the association of categorical variables and women's concerns about discrimination was performed using Pearson $\chi^{2}$ tests and Fisher's exact test. For quantitative variables, comparisons of means were conducted using Student's $t$ test.
The joint effect of selected variables on concerns about discrimination was analyzed using ordinal logistic regression. ${ }^{29}$ Ordinal logistic regression models were adjusted for potential confounding variables including the list from which telephone numbers were obtained and demographic variables such as age and education.

Most respondents provided data for all questions. For the ordinal logistic regression model reported in Tables 4 and 5, complete data were available from 177 of the 200 women $(88 \%)$. All analyses were conducted using the statistical software package SAS. ${ }^{30}$ Hypothesis tests were two-tailed and were declared statistically significant at the 5\% level. No corrections for multiple testing were used.

\section{RESULTS}

\section{Characteristics of the respondents}

Characteristics of respondents are displayed in Table 1. Respondents from the CJP list were slightly older than respondents in the RDD group. Characteristics of both groups were otherwise similar. Seventy-five percent of women had graduated from college. One third of respondents had a history of Tay Sachs testing. Approximately two thirds of the sample were married and had children. The mean BRCA1/2 knowledge score was 4 out of a possible 7 (SD \pm 1.4 ) (Table 2). The sociodemographic characteristics of this cohort are similar to those of the greater Boston Jewish population in which $73 \%$ of individuals have graduated from college, and $34 \%$ of households have minor children. ${ }^{24}$

\section{Concerns about group discrimination}

Of the 200 women surveyed, 142 (71\%) thought there were scientific reasons for testing Jews in particular for BRCA1/2 mutations, and only 33 (17\%) expressed concern or discomfort about Jews being offered BRCA1/2 testing (Table 3). Twenty-six (13\%) believed that BRCA1/2 testing will lead to increased anti-Semitism. Very few women surveyed believed that genetic testing of Jews reflected a belief that Jews were genetically inferior, and approximately half of respondents felt that research that looks for specific genes common to Jews as a group was good for the Jewish community. Responses were similar among respondents from the CJP list and the RDD list.

Table 1

Characteristics of study participants by source of telephone number

\begin{tabular}{|c|c|c|c|}
\hline Variable & $\begin{array}{c}\text { CJP } \\
\text { list } \\
(N=72)\end{array}$ & $\begin{array}{c}\text { RDD } \\
\text { list } \\
(N=128)\end{array}$ & $P$ value \\
\hline Age $($ mean $\pm S D$, yr $)$ & $49 \pm 12$ & $46 \pm 10$ & 0.04 \\
\hline Education (college graduate) & $75 \%$ & $74 \%$ & 0.75 \\
\hline Prior genetic testing & $16 \%$ & $24 \%$ & 0.15 \\
\hline Have children & $49 \%$ & $30 \%$ & 0.20 \\
\hline
\end{tabular}


Table 2

$B R C A 1 / 2$ knowledge and interest in predisposition testing

\begin{tabular}{lr}
\hline Variable & $N(\%)$ \\
\hline BRCA1/2 knowledge score ${ }^{a}$ & $26(13)$ \\
$1-2$ & $149(75)$ \\
$3-5$ & $25(12)$ \\
$6-7$ & \\
Interest in BRCA1/2 testing & $80(40)$ \\
No & $79(40)$ \\
Yes & $40(20)$ \\
Uncertain &
\end{tabular}

Table 3

Group discrimination concerns

\begin{tabular}{lc}
\hline Question & $N(\%)$ \\
\hline Are there scientific reasons for testing Jews? & $142(71)$ \\
Yes & $25(13)$ \\
No & $32(16)$ \\
Uncertain & \\
Are you concerned about BRCA1/2 testing being & \\
$\quad$ offered to Jewish women? & $33(17)$ \\
Yes & $162(83)$ \\
No & \\
Does genetic testing reflect a belief that Jews are & \\
$\quad$ genetically inferior? & $4(2)$ \\
Yes & $190(96)$ \\
No & $5(2)$ \\
Uncertain & \\
Will genetic testing increase anti-Semitism? & \\
Yes & \\
No & \\
Uncertain & \\
Is research which looks for specific genes & $11(13)$ \\
Good & $164(82)$ \\
Neither & $10(5)$ \\
\hline
\end{tabular}

\section{Perceptions of advantages and disadvantages of BRCA1/2 testing}

Respondents' attitudes toward the advantages of BRCA1/2 testing were assessed using a Likert scale of 1 to 10 , where 1 indicated not at all valuable and 10 indicated extremely valuable. Respondents rated the value of knowing that an individual would develop the disease in the future, even if there was nothing that could be done to prevent the disease, with a mean score of 5. A mean score of 9.6 was observed for the ability to detect breast cancer at an earlier stage. Obtaining information about children's risk of breast cancer received a mean score of 8.5.

Using a Likert scale from 1 to 10 where 1 meant no problem at all and 10 meant an extremely big problem, women's perceptions of the disadvantages of BRCA1/2 testing were as follows: the potential of insurance discrimination was rated a mean of 7.6, the possibility of increased anxiety resulting from knowledge of carrier status was rated a mean of 7.0, the fact that the results of BRCA1/2 testing will not tell the person tested when she will develop breast cancer but only that she is likely to develop it at some time in the future was rated a mean of 6.6, and the potential of employment discrimination was rated a mean of 3.7.

\section{Use of information from BRCA1/2 testing}

Most women surveyed said they would have more frequent mammograms [177 (89\%)] and do more breast self-exams [181 (91\%)] if they were found to carry a mutation in BRCA1/2. A smaller, but still substantial, proportion of women said they would change their diets [125 (64\%)] and exercise more [118 (61\%)] if they had a mutation in BRCA1/2.

\section{Predictors of interest in BRCA1/2 testing}

Forty percent of respondents indicated an interest in pursuing BRCA1/2 testing, while $40 \%$ indicated that they were not interested and $20 \%$ were uncertain (Table 2). In univariate analyses, factors associated with an interest in testing included an openness to having prophylactic mastectomies, valuing information about children's risk, valuing early detection of breast cancer, believing heredity significantly contributes to breast cancer, lack of anxiety associated with obtaining genetic information, and concern about genetic testing being offered to Jews (Table 4). We found no association between having a prior positive experience with genetic testing and interest in $B R C A 1 / 2$ testing. In multivariate models controlling for education, marital status, and the list from which the telephone number was obtained, the only factors that remained statistically significantly associated with an interest in testing were as follows: valuing information even if there were no treatment options, valuing information about children's risk, and believing heredity significantly contributes to breast cancer (Table 4). Individuals who were not interested in genetic testing were less likely to value genetic information if no treatment options existed, were less likely to value information about their children's risk of breast cancer, and were less likely to believe that heredity significantly contributes to breast cancer.

\section{Predictors of concern about genetic discrimination}

Women who were highly educated expressed more concern about genetic discrimination (Table 5). In univariate analysis, women who did not value genetic information if there were no treatment options, who were less interested in genetic testing, and who were more worried about employment discrimination expressed more concern about genetic discrimination. Individuals who were not interested or uncertain about their interest in genetic testing were slightly more concerned about 
Table 4

Correlates of interest in $B R C A 1 / 2$ testing $(N=177)$

\begin{tabular}{|c|c|c|c|c|}
\hline \multirow[b]{2}{*}{ Variable } & \multicolumn{2}{|c|}{ Unadjusted } & \multicolumn{2}{|c|}{ Adjusted $^{a}$} \\
\hline & OR $(95 \% \mathrm{CI})$ & $P$ value & OR $(95 \% \mathrm{CI})$ & $P$ value \\
\hline Age (years) & $0.98(0.95-1.0)$ & 0.05 & $0.95(0.95-0.98)$ & 0.001 \\
\hline Would have prophylactic mastectomies & $2.08(1.21-3.60)$ & 0.009 & $1.40(0.71-2.77)$ & 0.34 \\
\hline Value information if no treatment options & $1.22(1.12-1.32)$ & 0.0001 & $1.13(1.02-1.25)$ & 0.01 \\
\hline Value information about children's risk & $1.36(1.19-1.54)$ & 0.0001 & $1.24(1.06-1.44)$ & 0.01 \\
\hline Value early detection of breast cancer & $1.8(1.19-2.64)$ & 0.005 & $1.5(0.86-2.54)$ & 0.16 \\
\hline Believe heredity significantly contributes to breast cancer & $3.22(1.5-6.92)$ & 0.003 & $2.5(0.97-6.31)$ & 0.05 \\
\hline Anxiety associated with knowledge of genetic information & $0.88(0.81-0.97)$ & 0.012 & $0.97(0.87-1.09)$ & 0.61 \\
\hline Concern about testing being offered to Jews & $0.47(0.23-0.97)$ & 0.04 & $0.70(0.29-1.67)$ & 0.43 \\
\hline
\end{tabular}

The dependent variable was interest in genetic testing modeled as an ordinal outcome from not interested in pursuing genetic testing, to uncertain about interest, to interested in pursuing genetic testing. OR, odds ratio; $\mathrm{CI}$, confidence interval.

${ }^{a}$ Odds ratios are adjusted for education, marital status, and the list from which the telephone number was obtained.

Table 5

Correlates of concern about genetic discrimination $(N=177)$

\begin{tabular}{|c|c|c|c|c|}
\hline \multirow[b]{2}{*}{ Variable } & \multicolumn{2}{|c|}{ Unadjusted } & \multicolumn{2}{|c|}{ Adjusted $^{a}$} \\
\hline & OR $(95 \% \mathrm{CI})$ & $P$ value & OR $(95 \% \mathrm{CI})$ & $P$ value \\
\hline Age (years) & $0.56(0.27-1.15)$ & 0.11 & $0.95(0.95-0.98)$ & 0.28 \\
\hline College-educated $^{b}$ & $2.71(1.07-6.83)$ & 0.02 & $2.68(1.06-6.82)$ & 0.02 \\
\hline BRCA1/2 knowledge & $1.31(0.66-2.60)$ & 0.44 & $1.26(0.62-2.56)$ & 0.52 \\
\hline Have children & $0.58(0.27-1.27)$ & 0.18 & $0.43(0.14-1.31)$ & 0.14 \\
\hline Value information if no treatment options & $0.48(0.23-0.99)$ & 0.05 & $0.49(0.23-1.04)$ & 0.06 \\
\hline Interest in testing & $0.34(0.11-1.02)$ & 0.05 & $0.34(0.11-1.05)$ & 0.06 \\
\hline Value early detection of breast cancer & $0.78(0.31-1.99)$ & 0.61 & $0.88(0.34-2.29)$ & 0.79 \\
\hline Believe heredity significantly contributes to breast cancer & $0.59(0.26-1.36)$ & 0.22 & $0.52(0.22-1.23)$ & 0.14 \\
\hline Concern about employment discrimination & $2.01(1.00-4.02)$ & 0.05 & $1.82(0.88-3.75)$ & 0.11 \\
\hline Concern about health insurance discrimination & $2.39(0.94-6.07)$ & 0.07 & $2.00(0.77-5.20)$ & 0.16 \\
\hline
\end{tabular}

Respondents were considered to have concern about genetic discrimination if they responded yes to either or both of the following questions: "Do you have any concern or discomfort about Jewish women being invited to have this genetic test?" and "Do you think that participating in this testing will lead to increased anti-Semitism?"

${ }^{a}$ Odds ratios are adjusted for age, education, marital status, and the list from which the telephone number was obtained.

${ }^{b}$ Education was dichotomized into college-educated versus not college-educated. Greater education was associated with increased odds of having concern about genetic discrimination.

genetic discrimination. However, in a multivariate analysis, only being highly educated (master's degree or higher) was significantly associated with a concern about genetic discrimination.

\section{DISCUSSION}

We found that among a population sample of Jewish women, few women expressed concern or discomfort with the targeting of Jews for both genetic testing (17\%) and research (5\%). In fact, most women thought there were scientific reasons for testing Jews $(71 \%)$, and most felt that research that focused on Jews was either neutral or good (95\%). Concern about discrimination was significantly associated with being highly educated. We also found that interest in breast cancer susceptibility testing varied. After rating respondents' attitudes about a series of potential advantages and disadvantages of genetic testing for breast cancer susceptibility, $40 \%$ of respondents expressed interest in BRCA1/2 testing, $40 \%$ were not interested, and $20 \%$ were uncertain about whether they would be interested in BRCA1/2 testing for themselves. Increased interest in genetic testing was associated with a desire to obtain information about their children's risk of disease and valuing information for its own sake.

There have been few empirical studies on the attitudes of ethnic groups toward genetic testing and research. In a study of Canadian Jewish women with breast cancer, the decision to undergo $B R C A 1 / 2$ testing was influenced by a desire to con- 
tribute to research, potential benefit to family, curiosity, relief if not found to be a carrier, and the need to know. In that study, $28 \%$ of those surveyed expressed concern about insurance discrimination, $17 \%$ were concerned about the potential impact of genetic test results on marriage prospects for family members, and $14 \%$ expressed concern about the focus on the Jewish community. ${ }^{31}$ The results of our study add further support to these data, which suggest that although there is some concern about discrimination, it does not seem to be widespread among the population.

Interpreting the concerns about discrimination voiced by a minority of our study respondents and among some community Jewish leaders must be done within a historical context. In the early part of the 20th century, the United States enacted forced sterilization laws in pursuit of a eugenic plan to eliminate from the population undesirable characteristics. ${ }^{32}$ The fear of recreating abuses, which were committed in the name of eugenics through coercive policies imposed by governments, may underlie the concerns expressed by both community leaders and some respondents in our study. ${ }^{33}$ Jews were also the subject of Nazi eugenic attempts, and as a result of this experience there may be fear among some members of the Jewish population that information from genetic testing will lead to a societal perception that Jews as a group have defective genes. ${ }^{34}$ This perception could lead to insurance discrimination against Jews, result in societal pressure not to reproduce, or pressure women to abort a fetus with a genetic mutation. ${ }^{35}$ Although some community leaders have suggested that Jews not participate in genetic testing and research, these concerns about group discrimination do not seem to be shared by the majority of a population-based sample of Jewish women.

Although the majority of respondents in our study were not concerned about the potential for discrimination against Jews as individuals, the potential risks of discrimination may be even more significant at the level of social groups. Genetic researchers attempting to do population-based genetic variation research have considered and attempted to minimize genetic discrimination at the level of the individual and the family. ${ }^{36,37}$ How researchers achieve protections for entire ethnic or social groups, however, remains elusive. ${ }^{38}$ Guidelines have been developed to protect aboriginal communities, but their extension into less-cohesive communities, such as Ashkenazi Jews, may not be feasible. ${ }^{39,40}$ Some have suggested that the social group itself should be involved in the process of research. ${ }^{41,42}$ This is the process which was undertaken in Iceland when Decode Genetics ${ }^{43}$ proposed to create an electronic database of the country's health records that could be linked to individuals genotype. ${ }^{44,45}$ Part of the purpose of our study was to provide an example of the process of assessing the attitudes of a community before pursuing population-based genetic research. By engaging the community and assessing their concerns about the potentially negative consequences of genetic testing and research we hope to have provided a foundation for future research within the Ashkenazi Jewish population. Our research also demonstrates the feasibility of assessing a particular ethnic group's concerns about the broader social implications of scientific research.

There are several limitations to this study. First, before our survey, the women in our study may not have been well educated about the advantages and disadvantages of BRCA1/2 testing. The responses that we obtained might have been different if women had been given more time to contemplate the complex issues and ramifications of genetic testing. Although we attempted to educate the women throughout the course of the survey in an effort to obtain educated and stable responses, this process may not match the detailed and personalized information most women would receive if they were more closely considering genetic testing. Second, the sample size of this study was relatively small. It is possible that a larger study would find more variation in women's concerns about group discrimination.

The extraordinary power of genetic research on large populations must be balanced with the potential negative effects of that research on the particular populations studied and the potential advantages to individuals who may benefit from genetic information. Knowledge of a predisposition to a disease may give individuals the opportunity to prevent illness through increased surveillance or medical intervention. This benefit to individuals within a particular group must be assessed within the context of possible group stigmatization and discrimination. One way to help achieve this balance is to obtain particular populations' input and consent to research within their community.

\section{Acknowledgments}

Lisa Lehmann was supported by a National Research Service Award training grant (5 T32 PE11001) and the Harvard University Center for Ethics and the Professions. Research support was provided by a grant from the Woman's Cancer Program at the Dana-Farber Cancer Institute. The authors thank Lois Biener, $\mathrm{PhD}$, for her assistance with survey development and data collection.

\section{References}

1. Venter JC, Adams MD, Myers EW, Li PW, Mural RJ, Sutton GG. The sequence of the human genome. Science 2001;291:1304-1351.

2. International Human Genome Sequencing Consortium. Initial sequencing and analysis of the human genome. Nature 2001;409:860-921.

3. Breslow JL, Dammerman M. Genetic determinants of myocardial infarction. $A d v$ Exp Med Biol 1995;369:65-78.

4. Lynch HT, Smyrk TC. Hereditary colorectal cancer. Semin Oncol 1999;26:478-484.

5. Greene MH. The genetics of hereditary melanoma and nevi: 1998 update. Cancer 1999;86(suppl):1644-1657.

6. Ellisen LW, Haber DA. Hereditary breast cancer. Annu Rev Med 1998;49:425-436 [published correction appears in Annu Rev Med 1999;50:582].

7. Hilgers W, Kern SE. Molecular genetic basis of pancreatic adenocarcinoma. Genes Chromosomes Cancer 1999;26:1-12.

8. Calender A. Genetic testing in multiple endocrine neoplasia and related syndromes. Forum 1998;8:146-159.

9. Fleming S. Genetics of kidney tumours. Forum 1998;8:176-184.

10. Tobin SL, Chun N, Powell TM, McConnell LM. The genetics of Alzheimer disease and the application of molecular tests. Genet Test 1999;3:37-45.

11. Rothenberg K. Testimony before the Technology Subcommittee of the House Committee on Science. September 17, 1996.

12. Lehrman S. Jewish leaders seek genetic guidelines. Nature 1997;389:322. 


\section{Lehmann et al.}

13. Risch N, de Leon D, Ozelius L, Kramer P, Almasy L, Singer B, Fahn S, Breakefield X, Bressman S. Genetic analysis of idiopathic torsion dystonia in Ashkenazi Jews and their recent descent from a small founder population. Nat Genet 1995;9:152-159.

14. Levine M. Screening Jews and genes: a consideration of the ethics of genetic screening within the Jewish community. Genet Test 1999;3:207-213.

15. Duster T. Backdoor to eugenics. New York: Routledge, 1990.

16. Markel H. The stigma of disease: implications of genetic screening. Am J Med 1992; 93:209-215.

17. Chadwick R. The Icelandic database: do modern times need modern sagas? BMJ 1999;319:441-444.

18. Davis D. Groups, communities, and contested identities in genetic research. Hastings Cent Rep 2000;30:38-45.

19. Oddoux C, Struewing JP, Clayton CM, Neuhausen S, Brody LC, Kaback M, Haas B, Norton L, Borgen P, Jhanwar S, Goldgar D, Ostrer H, Offit K. The carrier frequency of the BRCA2 6174delT mutation among Ashkenazi Jewish individuals is approximately 1\%. Nat Genet 1995;11:198-200.

20. Warner E, Foulkes W, Goodwin P, Meschino W, Blondal J, Paterson C, Ozcelik H, Goss P, Allingham-Hawkins D, Hamel N, Di Prospero L, Contiga V, Serruya C, Klein M, Moslehi R, Honeyford J, Liede A, Glendon G, Brunet JS, Narod S. Prevalence and penetrance of $B R C A 1$ and $B R C A 2$ gene mutations in unselected Ashkenazi Jewish women with breast cancer. J Natl Cancer Inst 1999;91:1241-1247.

21. Abeliovich D, Kaduri L, Lerer I, Weinberg N, Amir G, Sagi M, Zlotogora J, Heching $\mathrm{N}$, Peretz T. The founder mutations 185delAG and 5382insC in BRCA1 and 6174 delT in BRCA2 appear in $60 \%$ of ovarian cancer and $30 \%$ of early onset breast cancer patients among Ashkenazi women. Am J Hum Genet 1997;60:505-514.

22. Gryfe R, Di Nicola N, Lal G, Gallinger S, Redston M. Inherited colorectal polyposis and cancer risk of the APC I1307K polymorphism. Am J Hum Genet 1999;64:378-384.

23. Coughlin SS, Miller DS. Public health perspectives on testing for colorectal cancer susceptibility genes. Am J Prev Med 1999;16:99-104.

24. Kessler EJ. The secret shake-up in the shiduch. Forward July 26, 1996:11.

25. Post M. Jewish women at risk of cancer face insurance bias. Jewish Bulletin of Northern California May 23, 1997.

26. Israel S. Comprehensive report on the 1995 CJP Demographic Study. Boston: CJP of Greater Boston, 1997.

27. Ford D, Easton DF, Peto J. Estimates of the gene frequency of BRCA1 and its contribution to breast and ovarian cancer incidence. Am J Hum Genet 1995;57:1457-1462.

28. Lerman C, Narod S, Schulman K, Hughes C, Gomez-Caminero A, Bonney G, Gold K, Trock B, Main D, Lynch J, Fulmore C, Snyder C, Lemon SJ, Conway T, Tonin P,
Lenoir G, Lynch H. BRCA1 testing in families with hereditary breast-ovarian cancer: a prospective study of patient decision making and outcomes. JAMA 1996;275: 1885-1892.

29. Hosmer DW, Lemeshow S. Applied logistic regression, 2nd ed. New York: John Wiley \& Sons, 2000.

30. SAS Institute. Changes and enhancements through release 6.12. Cary, NC: SAS Institute, 1997.

31. Phillips KA, Warner E, Meschino WS, Hunter J, Abdolell M, Glendon G, Andrulis IL, Goodwin PJ. Perceptions of Ashkenazi Jewish breast cancer patients on genetic testing for mutations in BRCA1 and BRCA2. Clin Genet 2000;57:376-383.

32. Caplan A, editor. When medicine went mad. Totowa, NJ: Humana, 1990.

33. Annas G, Grodin M, editors. The Nazi doctors and the Nuremberg Code. New York: Oxford University Press, 1992.

34. Davis DS. Groups, communities, and contested identities in genetic research. Hastings Cent Rep 2000;30:38-45.

35. Tendler M. International Conference on Judaism and Contemporary Medicine. New York, April 28, 1996. Available at: http://www.nijmbreast.

36. Geller L, Alper J, Billings P, Barash C, Beckwith J, Natowicz. Individual, family and societal dimensions of genetic discrimination: a case study analysis. Sci Eng Ethics 1996;29:71-81.

37. Hudson K, Rothernberg K, Andrews L, Kahn M, Collins F. Genetic discrimination and health insurance: an urgent need for reform. Science 1995;270:391-393.

38. Juengst ET. Groups as gatekeepers to genomic research: conceptually confusing, morally hazardous, and practically useless. Kennedy Inst Ethics J 1998;8:183-200.

39. Weijer C, Goldsand G, Emanuel EJ. Protecting communities in research: current guidelines and limits of extrapolation. Nat Genet 1999;23:275-280.

40. Davis DS. Groups, communities, and contested identities in genetic research. Hastings Cent Rep 2000;30:38-45.

41. Committee on Human Genome Diversity, National Research Council. Evaluating human genetic diversity. Washington, DC: National Academy Press, 1997.

42. Foster MW, Eisenbraun AJ, Carter TH. Community discourse as a supplement to informed consent for genetic research. Nat Genet 1997;17:277-279.

43. DeCODE genetics. www.database.is

44. Ministry of Health. Act on a health sector database. Reykjavik: Ministry of Health, 1998.

45. Duncan N. World Medical Association opposes Icelandic gene database. BMJ 1999; 318:1096. 